\title{
On-pump and off-pump coronary artery bypass grafting in patients with left main stem disease: A propensity score analysis
}

\author{
Michele Murzi, MD, ${ }^{\mathrm{a}}$ Massimo Caputo, MD, ${ }^{\mathrm{a}}$ Giuseppe Aresu, MD, ${ }^{\mathrm{a}}$ Simon Duggan, MD, ${ }^{\mathrm{a}}$ \\ Antonio Miceli, MD, ${ }^{\mathrm{b}}$ Mattia Glauber, MD, ${ }^{\mathrm{b}}$ and Gianni D. Angelini, MD, FRCS ${ }^{\mathrm{a}}$
}

\begin{abstract}
Objective: This study compared safety and efficacy between off-pump coronary artery bypass grafting $(\mathrm{OPCAB})$, a relatively new technique, and conventional on-pump coronary artery bypass grafting (CCAB) in patients with left main stem disease.
\end{abstract}

\begin{abstract}
Methods: In a retrospective, observational, cohort study of prospectively collected data on 2375 consecutive patients with left main stem disease undergoing isolated CABG (1297 OPCAB, 1078 CCAB) between April 1996 and December 2009 at the Bristol Heart Institute, 548 patients undergoing OPCAB were matched with 548 patients undergoing $\mathrm{CCAB}$ by propensity score.
\end{abstract}

\begin{abstract}
Results: After propensity matching, groups were comparable in preoperative characteristics. Relative to CCAB, OPCAB was associated with lower in-hospital mortality $(0.5 \%$ vs $2.9 \% ; P=.001)$, incidence of stroke $(0 \%$ vs $0.9 \% ; P=.02)$, postoperative renal dysfunction $(4.9 \%$ vs $10.8 \% ; P=.001)$, pulmonary complications $(10.2 \%$ vs $16.6 \% ; P=.002)$, and infectious complications $(3.5 \%$ vs $6.2 \% ; P=.03)$. The OPCAB group received fewer grafts than did the CCAB group $(2.7 \pm 0.7$ vs $3 \pm 0.7 ; P=.001)$ and had a lower rate of complete revascularization $(88.3 \%$ vs $92 \% ; P=.04)$. In multivariable analysis, cardiopulmonary bypass was confirmed to be an independent predictor of in-hospital mortality (odds ratio, 5.74; $P=.001$ ). Survivals at 1,5 , and 10 years were similar between groups (OPCAB, 96.8\%, 87.3\%, and 71.7\%; CCAB, 96.8\%, 88.6\%, and 69.8\%).
\end{abstract}

Conclusions: OPCAB in patients with left main stem disease is a safe procedure with reduced early morbidity and mortality and similar long-term survival to conventional on-pump revascularization. (J Thorac Cardiovasc Surg 2012;143:1382-8)

The presence of significant left main stem (LMS) coronary artery disease is a well-known risk factor for cardiac-related events and is associated with a 3-year survival as low as $37 \%$, depending on the degree of stenosis, left ventricular function, and associated coronary disease. ${ }^{1,2}$ Medical therapy alone confers a poor survival advantage relative to surgical revascularization,,$^{1,3,4}$ and the role of percutaneous revascularization techniques for critical LMS disease remains unclear. ${ }^{5,6}$ Off-pump coronary artery bypass grafting $(\mathrm{OPCAB})$ is now an established procedure, with results comparable to conventional coronary artery bypass $(\mathrm{CCAB})$ with cardiopulmonary bypass. ${ }^{7-9}$ Because of the hemodynamic instability associated with ventricular manipulation, however, patients with LMS coronary

From the Bristol Heart Institute, ${ }^{\mathrm{a}}$ University of Bristol, Bristol, United Kingdom; and

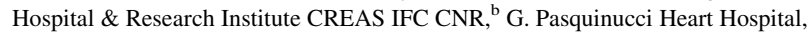
Massa, Italy.

Supported by the British Heart Foundation and the Bristol NIHR Biomedical Research Unit in Cardiovascular Medicine.

Disclosures: Authors have nothing to disclose with regard to commercial support.

Received for publication Sept 20, 2010; revisions received Feb 2, 2011; accepted for publication July 19, 2011; available ahead of print Aug 16, 2011.

Address for reprints: Gianni D. Angelini, MD, FRCS, Bristol Heart Institute, Bristol BS2 8HW, UK (E-mail: G.D.Angelini@bristol.ac.uk).

0022-5223/\$36.00

Copyright (c) 2012 by The American Association for Thoracic Surgery doi:10.1016/j.jtcvs.2011.07.035 artery disease have generally been excluded from OPCAB revascularization. ${ }^{10,11}$ Previous studies investigating the role of OPCAB in patients with LMS coronary artery disease have reported on small cohorts of patients and have lacked statistical adjustment to reduce the differences in selection bias. ${ }^{12-14}$ The aim of this study was therefore to evaluate the early outcomes and longterm survivals after $\mathrm{OPCAB}$ versus $\mathrm{CCAB}$ in a consecutive large cohort of patients with LMS coronary artery disease by conducting a propensity score matching analysis.

\section{MATERIALS AND METHODS \\ Patient Selection}

The study was approved by the clinical audit committee of the University Hospital Bristol NHS Foundation Trust to meet ethical and legal requirements, and individual consent was waived. This was a retrospective, observational cohort study of prospectively collected data from consecutive patients with LMS coronary artery disease who underwent isolated coronary artery bypass grafting at the Bristol Heart Institute between April 1996 and December 2009. The data collection form was entered into a database (Patient Analysis \& Tracking System; Dendrite Clinical Systems, London, UK) and included 5 sections that were filled in consecutively by anesthetists, surgeons, and intensive care unit, high-dependency unit, and ward nurses. The resulting base sample contained detailed clinical information on 2375 patients, 1297 (54.6\%) of whom underwent OPCAB and 1078 $(45.4 \%)$ of whom underwent CCAB. To reduce the effect of treatment selection bias and potential confounding, we used a propensity score matching analysis, ${ }^{15}$ which resulted in 548 patients who underwent OPCAB matched with an equal number of patients who underwent CCAB. 


\section{Abbreviations and Acronyms \\ $\mathrm{CCAB}=$ conventional coronary artery bypass grafting \\ LMS = left main stem \\ NSTS $=$ National Strategic Tracing Service \\ $\mathrm{OPCAB}=$ off-pump coronary artery bypass grafting}

\section{Definitions}

Critical LMS disease was defined as a stenosis of greater than $50 \%$ according to visual assessment of the preoperative coronary angiogram by the referring physician. In-hospital mortality included all deaths within 30 days of operation regardless of where death occurred and all deaths in hospital after 30 days among patients who had not been discharged after the index operation. A diagnosis of postoperative myocardial infarction was based on the presence of new Q waves longer than $0.04 \mathrm{~ms}$ or a reduction in $\mathrm{R}$ waves greater than $25 \%$ in at least 2 contiguous leads on electrocardiography. The need for pacing, arrhythmias, and inotropic requirements were recorded and defined as previously reported elsewhere. ${ }^{14}$ Pulmonary complications included chest infection, ventilation failure, reintubation, and tracheostomy. ${ }^{16}$ Postoperative blood loss was defined as total chest tube drainage. Neurologic complications included permanent and transient strokes. Renal complications included acute renal failure, defined as the requirement of hemodialysis or an elevated creatinine level ( $>200 \mathrm{mmol} / \mathrm{L})$. Infectious complications included septicemia and sternal and leg wound infections, defined by positive culture and requirement for antibiotic therapy. ${ }^{14}$

The completeness of revascularization was determined by comparing the number of distal anastomoses with the number of diseased coronary systems observed on the preoperative coronary angiogram. If the number of distal anastomoses performed equaled the total number of coronary systems with significant disease, the completeness of revascularization index was 1 . Patients who had more distal anastomoses performed than the number of vessels with angiographically significant disease had a completeness of revascularization index greater than 1 and were classified as having complete revascularization.

\section{Patient Survival}

Patient records were linked to the National Strategic Tracing Service (NSTS), which records all deaths in the United Kingdom. To establish current vital status, patients were matched against the NSTS according to name, National Health Service unique number, date of birth, sex, and postal code. All patients in this study were successfully matched against the NSTS database.

\section{Anesthetic, Surgical Technique, and Postoperative Management}

Anesthetic and surgical techniques were standardized for all patients and have been reported previously elsewhere. ${ }^{10,16}$ In brief, for patients undergoing $\mathrm{CCAB}$, cardiopulmonary bypass was instituted with the use of ascending aortic cannulation and 2-stage venous cannulation of the right atrium. The membrane oxygenator was primed with $1000 \mathrm{~mL}$ of Hartman crystalloid solution, $500 \mathrm{~mL}$ of Gelofusine (B. Braun Melsungen AG, Melsungen, Germany), $0.5-\mathrm{g} / \mathrm{kg}$ mannitol, $7 \mathrm{~mL} 10 \%$ calcium gluconate, and $6000 \mathrm{IU}$ heparin. Alpha-stat pH management was used, and the systemic temperature was kept between $34^{\circ} \mathrm{C}$ and $36^{\circ} \mathrm{C}$. Myocardial protection was achieved with intermittent hyperkalemic antegrade warm blood cardioplegia. ${ }^{17,18}$ For OPCAB surgery, the Bristol technique was used to expose the coronaries and provide stabilization to perform the anastomoses. ${ }^{10} \mathrm{At}$ the end of surgery, patients were transferred to the intensive care unit and managed according to the unit protocol. ${ }^{10,16}$

\section{Statistical Analysis}

Continuous data were expressed as mean $\pm \mathrm{SD}$, and categoric data were expressed as percentages. The Kolmogorov-Smirnov test was used to check for normality of data in the 2 groups before further analysis. Differences between $\mathrm{OPCAB}$ and $\mathrm{CCAB}$ groups were compared with the use of a $\chi^{2}$ test for categoric variables and $t$ or Wilcoxon rank sum tests, as appropriate, for continuous variables. To reduce the effects of selection bias and potential confounding in this observational study, we developed a propensity score analysis. The propensity for OPCAB was determined without regard to outcomes by the use of a nonparsimonious multiple logistic regression analysis. All the variables listed in Table 1, the surgeons (proficient in OP$\mathrm{CAB}$ or $\mathrm{CCAB}$ ), as well as years of operation (number of days of each operation from April 1 1996, divided by 365) were included in the analysis. A propensity score, indicating the predicted probability of receiving OPCAB treatment, was then calculated from the logistic equation for each patient. Finally, we used the propensity score to match patients undergoing OPCAB with those undergoing $\mathrm{CCAB}$ (1:1 match). Specifically, we matched each patient undergoing OPCAB patient with 1 undergoing $\mathrm{CCAB}$ who had a propensity score that was identical to 5 places. If this could not be done, we then proceeded to the next highest digit match (4-, 3-, 2-, and 1-digit) to make the best matches, in a hierarchic sequence until no more matches could be made. Stepwise, multivariable logistic regression modeling was used to identify independent risk factors for in-hospital mortality; a significance level of .05 was used for both entry and selection. Similarly, multivariable Cox proportional hazard modeling was used to identify independent risk factors for all-cause mortality. Covariates under consideration for all models were all baseline characteristics (as listed in Table 1), the completeness of revascularization, and the use of cardiopulmonary bypass. Results are reported as percentages and odds ratios or hazards ratios and $95 \%$ confidence intervals. Overall survival was estimated by using the Kaplan-Meier method and was expressed as a percentage. Differences in long-term survivals were assessed by log-rank tests.

All reported $P$ values are 2-sided. All statistical analyses were performed with SPSS statistical software (version 15.0; IBM Corporation, Armonk, NY) and StatsDirect statistical software (version 2.7.2; StatsDirect Ltd, Altrincham, UK).

\section{RESULTS}

During the study period, 2375 patients with LMS coronary artery disease underwent isolated coronary artery bypass grafting; of these, 1297 patients $(54.6 \%$ ) underwent OPCAB and $1078(45.4 \%)$ underwent CCAB. Baseline characteristics of the study population are shown in Table 1. Compared with the $\mathrm{CCAB}$ group, patients who underwent $\mathrm{OPCAB}$ were older, had a higher prevalence of hypertension, and were more likely to require an urgent operation. In addition, they had more limited coronary artery disease and better Canadian Cardiovascular Society functional class and New York Heart Association (NYHA) functional class.

After propensity score matching, there were 548 matched pairs of patients (Table 1). In the matched cohorts, there was no longer any significant difference between the 2 groups for any covariate. OPCAB was associated with lower early mortality than was $\mathrm{CCAB}(P=.001)$. Moreover, patients undergoing $\mathrm{OPCAB}$ were less likely to have stroke $(P=.02)$, postoperative renal dysfunction $(P=.001)$, pulmonary complications $(P=.002)$, and infectious 
TABLE 1. Baseline characteristics of the entire cohort and propensity-matched patients

\begin{tabular}{|c|c|c|c|c|c|c|}
\hline \multirow[b]{2}{*}{ Variable } & \multicolumn{3}{|c|}{ All patients } & \multicolumn{3}{|c|}{ Propensity-matched patients } \\
\hline & $\begin{array}{c}\text { OPCAB } \\
(\mathbf{n}=\mathbf{1 2 9 7})\end{array}$ & $\begin{array}{c}\text { CCAB } \\
(n=1078)\end{array}$ & $P$ value & $\begin{array}{c}\text { OPCAB } \\
(n=548)\end{array}$ & $\begin{array}{c}\text { CCAB } \\
(n=548)\end{array}$ & $P$ value \\
\hline $\operatorname{Age}(y$, mean $\pm S D)$ & $66.4 \pm 9.2$ & $64.5 \pm 9$ & .001 & $65.7 \pm 9.3$ & $66.2 \pm 8.7$ & .3 \\
\hline Body mass index $\left(\mathrm{kg} / \mathrm{m}^{2}\right.$, mean $\left.\pm \mathrm{SD}\right)$ & $28.2 \pm 5.1$ & $27.9 \pm 4.8$ & .2 & $27.4 \pm 0.5$ & $27.2 \pm 0.4$ & .2 \\
\hline Female sex (no.) & $233(24.8 \%)$ & $1047(25.1 \%)$ & .8 & $109(19.7 \%)$ & $105(19.2 \%)$ & .7 \\
\hline Canadian Cardiovascular Society class (mean \pm SD) & $2.5 \pm 1.1$ & $2.6 \pm 1$ & .01 & $2.5 \pm 1.1$ & $2.5 \pm 1.1$ & .7 \\
\hline New York Heart Association functional class (mean \pm SD) & $2 \pm 0.8$ & $2.1 \pm 0.8$ & .01 & $2 \pm 0.8$ & $2 \pm 0.7$ & .6 \\
\hline Diabetes mellitus (no.) & $257(19.8 \%)$ & $205(19 \%)$ & 6 & $114(20.8 \%)$ & $113(20.6 \%)$ & .9 \\
\hline Hypertension (no.) & $948(73.1 \%)$ & $717(66.5 \%)$ & .01 & $383(69.9 \%)$ & $387(70.6 \%)$ & .8 \\
\hline Cerebrovascular disease (no.) & $114(8.8 \%)$ & $88(8.2 \%)$ & .5 & $46(8.4 \%)$ & $53(9.7 \%)$ & .4 \\
\hline Vascular disease (no.) & $147(11.3 \%)$ & $100(9.3 \%)$ & .1 & $51(9.3 \%)$ & $61(11.1 \%)$ & .3 \\
\hline Chronic obstructive pulmonary disease (no.) & $155(12 \%)$ & $113(10.5 \%)$ & .2 & $64(11.7 \%)$ & $67(12.2 \%)$ & .8 \\
\hline History of atrial fibrillation (no.) & $43(3.3 \%)$ & $3.4(3.2 \%)$ & .9 & $18(3.3 \%)$ & $15(2.7 \%)$ & .6 \\
\hline Creatinine $(\mathrm{mol} / \mathrm{L}$, mean $\pm \mathrm{SD})$ & $109 \pm 37$ & $111 \pm 34$ & .1 & $112 \pm 47$ & $111 \pm 37$ & .7 \\
\hline Ejection fraction $<30 \%$ (no.) & $63(4.9 \%)$ & $66(4.1 \%)$ & .08 & $29(5.3 \%)$ & $24(4.4 \%)$ & .5 \\
\hline Previous myocardial infarction (no.) & $573(44.2 \%)$ & $508(47.1 \%)$ & .1 & $252(51.2 \%)$ & $272(47.8 \%)$ & .6 \\
\hline Previous percutaneous coronary intervention (no.) & $64(4.9 \%)$ & $43(4 \%)$ & .2 & $24(4.4 \%)$ & $25(4.6 \%)$ & .9 \\
\hline Reoperative surgery (no.) & $25(1.9 \%)$ & $62(1.6 \%)$ & .4 & $10(1.8 \%)$ & $14(1.6 \%)$ & .4 \\
\hline Preoperative intra-aortic balloon pump use (no.) & $21(1.6 \%)$ & $26(2.4 \%)$ & .1 & $18(3.3 \%)$ & $12(3.1 \%)$ & .2 \\
\hline Urgent operation (no.) & $795(61.3 \%)$ & $291(27 \%)$ & .001 & $241(44.1 \%)$ & $231(42.3 \%)$ & .5 \\
\hline EuroSCORE (no.) & $4.1 \pm 2.8$ & $4.5 \pm 3.2$ & .07 & $4.1 \pm 2.7$ & $4.1 \pm 2.7$ & .7 \\
\hline Diseased coronary arteries (mean $\pm \mathrm{SD}$ ) & $2.67 \pm 0.5$ & $2.78 \pm 0.5$ & .001 & $2.71 \pm 0.5$ & $2.71 \pm 0.4$ & .1 \\
\hline
\end{tabular}

$O P C A B$, Off-pump coronary artery bypass grafting; $C C A B$, conventional coronary artery bypass grafting.

complications $(P=.03)$ than were patients undergoing $\mathrm{CCAB}$. Patients undergoing OPCAB a significantly lower needs for postoperative intra-aortic balloon pump $(P=.03)$ and inotropic supports $(P=.004)$, but no difference was found in the incidence of postoperative myocardial infarction $(P=.5$; Table 2$)$.
The OPCAB group received fewer coronary grafts $(2.7 \pm$ 0.7 vs $3 \pm 0.7 ; P=.001)$ than the CCAB group and also had a lower completeness of revascularization index $(1 \pm 0.3 \mathrm{vs}$ $1.1 \pm 0.3 ; P=.01)$ and a lower rate of completeness of revascularization $(P=.04)$ than the CCAB group. In addition, the OPCAB group had a shorter intensive care unit stay $(P=.01)$.

TABLE 2. Clinical outcomes of propensity-matched patients

\begin{tabular}{|c|c|c|c|}
\hline Variables & $\begin{array}{c}\text { OPCAB } \\
(n=548)\end{array}$ & $\begin{array}{c}\text { CCAB } \\
(n=548)\end{array}$ & $P$ value \\
\hline No. of grafts (mean $\pm \mathrm{SD})$ & $2.7 \pm 0.7$ & $3 \pm 0.7$ & .001 \\
\hline Completeness of revascularization index $($ mean $\pm \mathrm{SD})$ & $1 \pm 0.3$ & $1.1 \pm 0.3$ & .001 \\
\hline Complete revascularization (no.) & $484(88.3 \%)$ & $504(92 \%)$ & .04 \\
\hline In hospital mortality (no.) & $3(0.5 \%)$ & $16(2.9 \%)$ & .001 \\
\hline Perioperative myocardial infarction (no.) & $25(4.6 \%)$ & $20(3.6 \%)$ & .5 \\
\hline Postoperative atrial fibrillation (no.) & $113(20.6 \%)$ & $147(26.8 \%)$ & .01 \\
\hline Postoperative intra-aortic balloon pump (no.) & $14(2.6 \%)$ & $27(4.9 \%)$ & .03 \\
\hline Inotropic support (no.) & $208(38 \%)$ & $255(46.5 \%)$ & .004 \\
\hline Transient cerebrovascular accident (no.) & $2(0.4 \%)$ & $2(0.4 \%)$ & .9 \\
\hline Permanent cerebrovascular accident (no.) & $0(0 \%)$ & $5(0.9 \%)$ & .02 \\
\hline Renal dysfunction (no.) & $27(4.9 \%)$ & $59(10.8 \%)$ & .001 \\
\hline Hemodialysis (no.) & $3(0.5 \%)$ & $8(1.5 \%)$ & .1 \\
\hline Infectious complications & $19(3.5 \%)$ & $34(6.2 \%)$ & .03 \\
\hline Gastrointestinal complications (no.) & $4(0.7 \%)$ & $7(1.3 \%)$ & .3 \\
\hline Pulmonary complications (no.) & $56(10.2 \%)$ & $91(16.6 \%)$ & .002 \\
\hline Blood loss $(\mathrm{mL}$, mean $\pm \mathrm{SD})$ & $768 \pm 382$ & $814 \pm 461$ & .4 \\
\hline Reoperation for bleeding & $8(1.5 \%)$ & $15(2.7 \%)$ & .1 \\
\hline Intensive care unit stay $(\mathrm{d}$, mean $\pm \mathrm{SD})$ & $1.34 \pm 1.1$ & $1.48 \pm 1.1$ & .04 \\
\hline Hospital stay $(\mathrm{d}$, mean $\pm \mathrm{SD})$ & $8.1 \pm 0.2$ & $8.5 \pm 0.2$ & .5 \\
\hline
\end{tabular}

$O P C A B$, Off-pump coronary artery bypass grafting; $C C A B$, conventional coronary artery bypass grafting. 
TABLE 3. Multivariate analysis of in-hospital and long-term mortalities in propensity-matched patients

\begin{tabular}{lccc}
\hline \multicolumn{1}{c}{ Variable } & Odds/hazard ratio & $\mathbf{9 5} \%$ Confidence interval & $P$ value \\
\hline In-hospital mortality & & & \\
$\quad$ Cardiopulmonary bypass & 5.74 & $1.33-37.24$ & .001 \\
Diabetes & 3.48 & $1.46-15.64$ & .03 \\
$\quad$ Urgent operation & 5.83 & $1.42-24.35$ & .001 \\
Long-term mortality & & & \\
Age & 1.053 & $1.030-1.076$ & .001 \\
Diabetes & 1.407 & $0.981-2.018$ & .05 \\
COPD & 1.558 & $1.011-2.401$ & .04 \\
Vascular disease & 1.932 & $1.266-2.950$ & .002 \\
Incomplete revascularization & 1.533 & $0.942-2.496$ & .086 \\
\hline
\end{tabular}

COPD, Chronic obstructive pulmonary disease.

The multivariable regression analysis revealed that the use of cardiopulmonary bypass was an independent risk factor for in-hospital morality (odds ratio, 5.74; 95\% confidence interval, $1.33-37.24 ; P=.001)$. Other independent predictors of mortality included diabetes and operative priority (Table 3).

Follow-up (100\% complete) was similar between the 2 groups (OPCAB, $50.5 \pm 31.2$ months vs $\mathrm{CCAB}, 54.4 \pm$ 34.1 months; $P=.5$ ). The 1-, 5- and 10-year survivals were similar in the 2 groups (OPCAB, 96.8\%, 87.3\%, and $71.7 \%$ vs $\mathrm{CCAB}, 96.8 \%, 88.6 \%$, and $69.8 \%$; Figure 1). Advanced age, chronic obstructive pulmonary disease, diabetes, peripheral vascular disease, and incomplete revascularization were associated with reduced survival (Table 3). Finally, CCAB was not associated with worse survival than was OPCAB. During the study period, there was a steady increase in the use of OPCAB to treat patients with LMS coronary artery disease, from $2.0 \%$ of the total in 1996 to $50 \%$ in 2001 and $75.3 \%$ in 2009 . Clinical

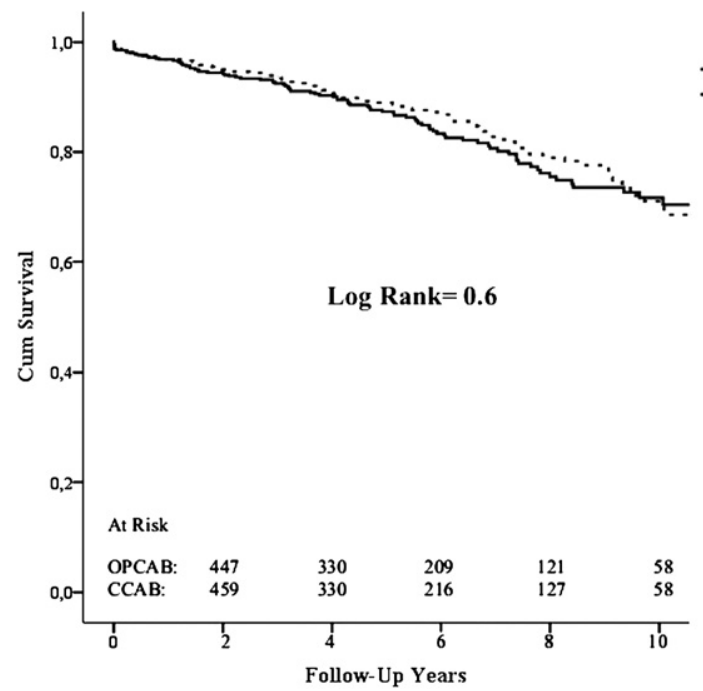

FIGURE 1. Kaplan-Meier survival curves for the propensity-matched patients. $O P C A B$, Off-pump coronary artery bypass grafting; $C C A B$, conventional on-pump coronary artery bypass grafting. outcomes of the entire cohort study population are reported in Appendix 1 and 2.

\section{DISCUSSION}

Our study demonstrates that OPCAB is safe for patients with LMS coronary artery disease and is associated with improved early morbidity and mortality and similar longterm survival with respect to CCAB.

Hemodynamic instability that may occur while performing revascularization on a beating heart is often cited as the main reason for not using the OPCAB technique to treat patients with critical LMS disease. ${ }^{10,11}$ After encouraging early pioneering results, ${ }^{19,20}$ however, a few studies have suggested potential benefits of OPCAB in this group of patients. Dewey and colleagues ${ }^{12}$ reported a lower perioperative mortality among 100 patients undergoing OPCAB compared with 723 undergoing $\mathrm{CCAB}$ and identifying the use of cardiopulmonary bypass as an independent predictor of in-hospital mortality (hazard ratio, 7.3; 95\% confidence interval, 1.3-138.3). Virani and associates ${ }^{13}$ showed similar mortalities in both groups, and a study from our institution reported lower requirements for inotropes and transfusion and a slightly shorter hospital stay for OPCAB compared with $\mathrm{CCAB} .{ }^{14} \mathrm{Lu}$ and associates ${ }^{21}$ analyzed the results of 1197 patients with LMS coronary artery disease (259 OP$\mathrm{CAB}$ vs $938 \mathrm{CCAB})$. They reported comparable outcomes between the 2 groups and concluded that LMS coronary artery disease should not represent a contraindication to OPCAB. All these studies were carried out on relatively small numbers of patients undergoing OPCAB and often reflected the initial experience of these Institutions with the technique. In contrast, our study is based on a large cohort of patients operated on over a period of 15 years. The number of patients presenting with a LMS coronary artery disease and the use of OPCAB steadily increased during the study period, reflecting our increasing experience with the technique.

The theoretic and practical advantages of avoiding cardiopulmonary bypass and related systemic inflammatory response may have contributed in our study to the lower rate 
of postoperative renal dysfunction, pulmonary complications, and infectious complications in our $\mathrm{OPCAB}$ group relative to our $\mathrm{CCAB}$ group. The global ischemia associated with cardiopulmonary bypass and cardioplegic arrest might explain the higher requirements of postoperative inotropic support and intra-aortic balloon pump use observed in the $\mathrm{CCAB}$ group relative to the OPCAB group.

The myocardial protection used in our study has been suggested to be associated with a higher incidence of myocardial necrosis and dysfunction, especially during the revascularization of the acutely ischemic myocardium, ${ }^{22}$ and retrograde cardioplegia has been proposed as a superior technique. Drawbacks associated with retrograde perfusion, however, such as myocardial edema and coronary sinus rupture, have caused many investigators to support the antegrade route alone even for patients with severe coronary artery disease. ${ }^{23,24}$ At the Bristol Heart Institute, we have used intermittent antegrade warm blood cardioplegia supplemented with magnesium since 1996 and have demonstrated its efficacy and safety. ${ }^{17,18}$ All these studies included urgent operations and patients in unstable condition and have consistently shown good hospital outcomes and lower release of markers of myocardial injury.

Patients undergoing $\mathrm{OPCAB}$ received fewer grafts and had a lower rate of completeness of revascularization than did those undergoing CCAB. This finding is consistent with other reports. ${ }^{3-14}$ Our database does not contain variables on the quality of coronary arteries, so it is difficult to know whether this difference in completeness of revascularization was due to patient characteristics or to technical challenges with the OPCAB procedure. Despite incomplete revascularization in the OPCAB group, survivals at 1,5 , and 10 years were similar between the 2 groups.

It is possible that a longer follow-up period might reveal a decreased long-term survival associated with incomplete revascularization in OPCAB. Indeed, it is important to note that when comparing the entire cohort study population, OPCAB was associated with both a higher incidence of incomplete revascularization and a reduced long-term survival relative to (Appendix 1 and 2).

\section{Study Limitations}

This study is based on a retrospective analysis of our large, institutional, observational, prospectively collected database. Propensity score analysis is simply a method to reduce bias in observational studies, and the matching was limited by available variables. The definition we used for revascularization is likely to have overestimated the proportion of patients who had completeness of revascularization, because patients may have had more than 1 graft to the same coronary system. The definition has the advantage of being simple and transparent, however, and the Bypass
Angioplasty Revascularization Investigation investigators found that their results were not markedly affected by using different definitions, including that used here. ${ }^{25}$

Even though the multivariable logistic regression identified the use of cardiopulmonary bypass as an independent predictor of in-hospital mortality, this analysis is limited by the low number of events (19 deaths), which may have affected the result, as shown by a wide confidence interval. Another limitation of this study is the use of all-cause mortality data, reliably obtained from the NSTS, rather than the more specific but less readily available cardiac-related mortality data. The study also did not address the relative incidences of nonfatal cardiac-related events and the requirements for repeated revascularization between the respective groups during the follow-up period.

\section{CONCLUSIONS}

In conclusion, our study demonstrates that in patients with LMS disease, OPCAB surgery is safe and associated with improved early clinical outcomes and similar long term survival compared with CCAB. A longer follow-up is required to understand the effects of incomplete revascularization in this subset of patients.

\section{References}

1. Brinker J. The left main facts: faced, spun, but alas too few. J Am Coll Cardiol. 2008;51:893-8.

2. Conley MJ, Ely RL, Kisslo J, Lee KL, McNeer JF, Rosati RA. The prognostic spectrum of left main stenosis. Circulation. 1978;57:947-52.

3. Caracciolo EA, Davis KB, Sopko G, Kaise GC, Corley SD, Schaff H, et al. Comparison of surgical and medical group survival in patients with left main coronary artery disease. Long-term CASS experience. Circulation. 1995;91: 2325-34.

4. Takaro T, Peduzzi P, Detre KM, Hultgren HN, Murphy ML, van der Bel-Kahn J, et al. Survival in subgroups of patients with left main coronary artery disease. Veterans Administration Cooperative Study of Surgery for Coronary Arterial Occlusive Disease. Circulation. 1982;66:14-22.

5. Morice MC, Serruys PW, Kappetein AP, Feldman TE, Ståhle E, Colombo A, et al. Outcomes in patients with de novo left main disease treated with either percutaneous coronary intervention using paclitaxel-eluting stents or coronary artery bypass graft treatment in the Synergy Between Percutaneous Coronary Intervention with TAXUS and Cardiac Surgery (SYNTAX) trial. Circulation. 2010;121:2645-53.

6. Seung KB, Park DW, Kim YH, Lee SW, Lee CW, Hong MK, et al. Stents versus coronary-artery bypass grafting for left main coronary artery disease. $N$ Engl $\mathrm{J}$ Med. 2008;358:1781-92.

7. Angelini GD, Culliford L, Smith DK, Hamilton MCK, Murphy GJ, Ascione R, et al. Effects of on- and off-pump coronary artery surgery on graft patency, survival, and health-related quality of life: long-term follow-up of 2 randomized controlled trials. J Thorac Cardiovasc Surg. 2009;137:295-303.

8. Ascione R, Williams S, Lloyd CT, Sundaramoorthi T, Pitsis AA, Angelini GD. Reduced postoperative blood loss and transfusion requirement after beatingheart coronary operations: a prospective randomized study. J Thorac Cardiovasc Surg. 2001;121:689-96

9. Ascione R, Lloyd CT, Underwood MJ, Lotto AA, Pitsis AA, Angelini GD. Economic outcome of off-pump coronary artery bypass surgery: a prospective randomized study. Ann Thorac Surg. 1999;6:2237-42.

10. Watters MP, Ascione R, Ryder IG, Ciulli F, Pitsis AA, Angelini GD. Haemodynamic changes during beating heart coronary surgery with the 'Bristol Technique'. Eur J Cardiothorac Surg. 2001;19:34-40.

11. Brown PM Jr, Kim VB, Boyer BJ, Lust RM, Chitwood WR Jr, Elbeery JR. Regional left ventricular systolic function in humans during off-pump coronary bypass surgery. Circulation. 1999;100(19 Suppl):125-7. 
12. Dewey TM, Magee MJ, Edgerton JR, Mathison M, Tennison D, Mack MJ. Offpump bypass grafting is safe in patients with left main coronary disease. Ann Thorac Surg. 2001;72:788-92.

13. Virani SS, Lombardi P, Tehrani H, Masroor S, Yassin S, Salerno T, et al. Offpump coronary artery grafting in patients with left main coronary artery disease. J Card Surg. 2005;20:537-41.

14. Yeatman M, Caputo M, Ascione R, Ciulli F, Angelini GD. Off-pump coronary arteries bypass surgery for critical left main stem disease: safety, efficacy and outcome. Eur J Cardiothorac Surg. 2001;19:239-44.

15. Blackstone EH. Comparing apples and oranges. J Thorac Cardiovasc Surg. 2002; 123:8-15.

16. Ascione R, Caputo M, Calori G, Lloyd CT, Underwood MJ, Angelini GD. Predictors of atrial fibrillation after conventional and beating heart coronary surgery: a prospective, randomized study. Circulation. 2000;102: 1530-5.

17. Yeatman M, Caputo M, Narayan P, Lotto AA, Ascione R, Angelini GD. Magnesium-supplemented warm blood cardioplegia in patients undergoing coronary artery revascularization. Ann Thorac Surg. 2002;73:112-8.

18. Caputo M, Bryan AJ, Calafiore AM, Suleiman MS, Angelini GD. Intermittent antegrade hyperkalaemic warm blood cardioplegia supplemented with magnesium prevents myocardial substrate derangement in patients undergoing coronary artery bypass surgery. Eur J Cardiothorac Surg. 1998;14: 596-601.
19. Louagie YA, Gonzalez ME, Schroder E. Off-pump myocardial revascularization for left main stem disease in a high-risk patient. Acta Chir Belg. 1999;99:309-11.

20. Cartier R, Brann S, Martineau R, Couturier A. [Left main coronary artery stenosis and revascularization in the beating heart. Short- and long-term experience] Ann Chir. 1999;53:701-5.

21. Lu JC, Grayson AD, Pullan MD. On-pump versus off-pump surgical revascularization for left main stem stenosis: risk adjusted outcomes. Ann Thorac Surg. 2005;80:136-42.

22. Matsuura H, Lazar HL, Yang XM, Rivers S, Treanor PR, Shemin RJ. Detrimental effects of interrupting warm blood cardioplegia during coronary revascularization. J Thorac Cardiovasc Surg. 1993;106:357-61.

23. Noyez L, van Son J, van der Werf T, Knape JT, Gimbrère J, van Asten WN, et al Retrograde versus antegrade delivery of cardioplegic solution in myocardial revascularization. A clinical trial in patients with three-vessel coronary disease who underwent myocardial revascularization with extensive use of the internal mammary artery. J Thorac Cardiovasc Surg. 1993;105:854-63.

24. Kaukoranta PK, Lepojärvi MV, Kiviluoma KT, Ylitalo KV, Peuhkurinen KJ. Myocardial protection during antegrade versus retrograde cardioplegia. Ann Thorac Surg. 1998;66:755-61.

25. Vander Salm TJ, Kip KE, Jones RH, Schaff HV, Shemin RJ, Aldea GS, et al What constitutes optimal surgical revascularization? Answers from the Bypass Angioplasty Revascularization Investigation (BARI). J Am Coll Cardiol. 2002; 39:565-72.

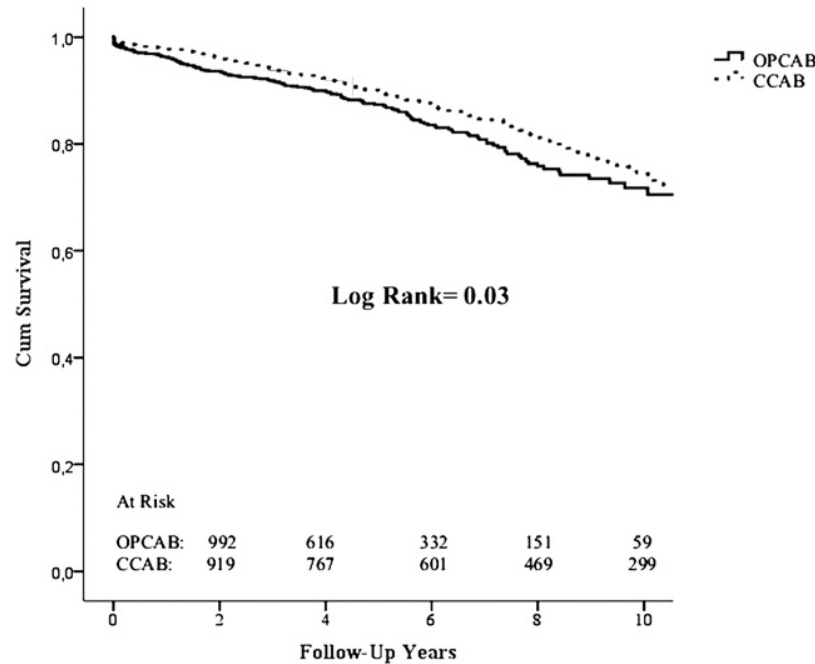

APPENDIX 1. Kaplan-Meier survival curves for the entire cohort study population. The 1-, 5-, and 10-year survivals significantly differed between the 2 groups (off-pump, $96.2 \%, 87.2 \%$, and $70.5 \%$ vs on-pump $97.6 \%$, $89.9 \%$, and $74.2 \%$ ). $O P C A B$, Off-pump coronary artery bypass grafting; $C C A B$, conventional on-pump coronary artery bypass grafting. 
APPENDIX 2. Clinical outcomes of the entire cohort study population

\begin{tabular}{|c|c|c|c|}
\hline Variables & $\begin{array}{c}\text { OPCAB } \\
(\mathbf{n}=\mathbf{1 2 9 7}) \\
\end{array}$ & $\begin{array}{c}\text { CCAB } \\
(\mathbf{n}=\mathbf{1 0 7 8}) \\
\end{array}$ & $P$ value \\
\hline No. of grafts $($ mean $\pm \mathrm{SD})$ & $2.7 \pm 0.7$ & $3 \pm 0.7$ & .001 \\
\hline Completeness of revascularization index (mean $\pm \mathrm{SD}$ ) & $1 \pm 0.3$ & $1.1 \pm 0.3$ & .001 \\
\hline Complete revascularization (no.) & $1126(86.7 \%)$ & $992(92.1 \%)$ & .001 \\
\hline In-hospital mortality (no.) & $11(0.8 \%)$ & $30(2.8 \%)$ & .001 \\
\hline Perioperative myocardial infarction (no.) & $45(3.5 \%)$ & $31(2.9 \%)$ & .4 \\
\hline Postoperative atrial fibrillation (no.) & $276(21.3 \%)$ & $296(27.5 \%)$ & .001 \\
\hline Postoperative intra-aortic balloon pump (no.) & $33(2.6 \%)$ & $43(4.5 \%)$ & .01 \\
\hline Inotropic support (no.) & $509(39.2 \%)$ & $527(48.9 \%)$ & .001 \\
\hline Transient cerebrovascular accident (no.) & $3(0.2 \%)$ & $4(0.4 \%)$ & .5 \\
\hline Permanent cerebrovascular accident (no.) & $1(0.1 \%)$ & $8(0.7 \%)$ & .01 \\
\hline Renal dysfunction (no.) & $84(6.5 \%)$ & $115(10.7 \%)$ & .001 \\
\hline Hemodialysis (no.) & $8(0.6 \%)$ & $20(1.9 \%)$ & .005 \\
\hline Infectious complications (no.) & $44(3.4 \%)$ & $65(6 \%)$ & .002 \\
\hline Gastrointestinal complications (no.) & $17(1.3 \%)$ & $15(1.4 \%)$ & .8 \\
\hline Pulmonary complications (no.) & $146(11.2 \%)$ & $181(16.8 \%)$ & .001 \\
\hline Blood loss $(\mathrm{mL}$, mean $\pm \mathrm{SD})$ & $812 \pm 671$ & $848 \pm 743$ & .2 \\
\hline Reoperation for bleeding (no.) & $24(1.8 \%)$ & $43(4 \%)$ & .002 \\
\hline Intensive care unit stay $(\mathrm{d}$, mean $\pm \mathrm{SD})$ & $1.4 \pm 1$ & $1.8 \pm 2.2$ & .01 \\
\hline Hospital stay $(\mathrm{d}$, mean $\pm \mathrm{SD})$ & $8.1 \pm 0.2$ & $8.5 \pm 0.2$ & .5 \\
\hline
\end{tabular}

$O P C A B$, Off-pump coronary artery bypass grafting; $C C A B$, conventional coronary artery bypass grafting. 